38

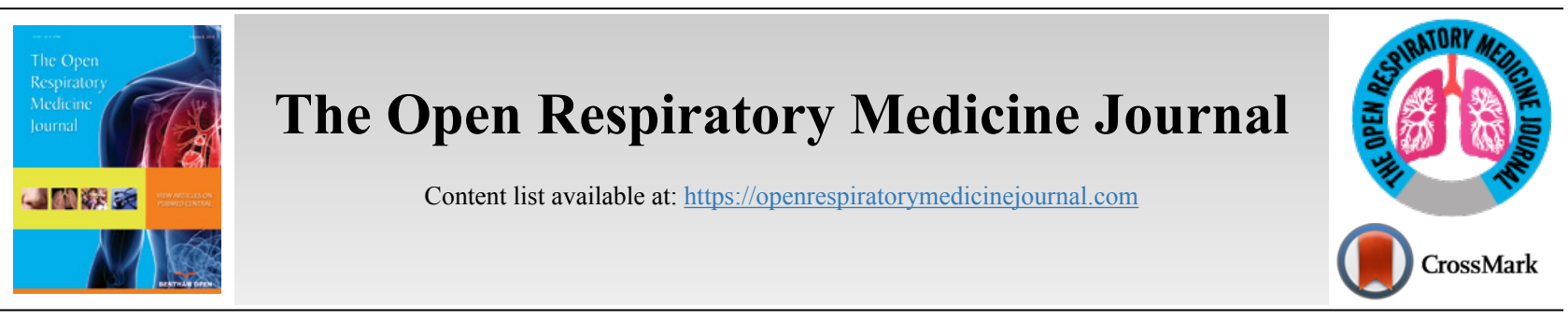

RESEARCH ARTICLE

\title{
Sonographically Measured Improvement in Diaphragmatic Mobility and Outcomes Among Patients Requiring Prolonged Weaning from the Ventilator
}

\author{
N Gibis ${ }^{1}$, A Schulz ${ }^{1}$, S Vonderbank ${ }^{1}$, M Boyko ${ }^{1}$, H Gürleyen ${ }^{1}$, X Schulz ${ }^{2}$ and A Bastian ${ }^{1, *}$ \\ ${ }^{\prime}$ Marienkrankenhaus Kassel, Marburger Str. 85, 34127 Kassel, Germany \\ ${ }^{2}$ Department of Medical Statistics, University Medical Center Göttingen, Georg-August-Universität, Humboldtallee 32, 37073 Göttingen, Germany
}

\begin{abstract}
:
Background:

The need of prolonged weaning from the ventilator is a well-known predictor of an unfavorable patients`outcome. Diaphragmatic dysfunction is a serious problem for these patients. We wanted to determine the survival in patients who were already intubated for more than 4 weeks before they were admitted to our weaning unit. In this prospective study, we wanted to investigate if the diaphragmatic function could improve or was related to survival over an 18 months follow up period.

\section{Methods:}

84 patients were included when they were able to breathe at least 10 minutes over a t-piece and sit upright for at least 5 minutes. The diaphragmatic function was estimated sonographically using the up and downward movement of the lung silhouette. Sonographic follow-ups were performed for over 18 months. The survival rate, outcome and changes in diaphragm mobility were investigated.

Results:

a) Survival: 49 patients (58\%) survived the 18 months follow up period - 30 had a good outcome; 19 needed assistance. b) Survival in relation to diaphragm mobility: If diaphragmatic mobility improved $\geq 15.5 \mathrm{~mm}$ on the left side, the probability of survival was $94 \%$ with a probability of $76 \%$ to have a satisfying outcome.

Conclusion:

Survival and outcome of prolonged weaning were significantly better when sonographically measured the mobility of left hemidiaphragm improved.
\end{abstract}

Keywords: Diaphragm, Weaning, Ultrasound, Outcome, Ventilator, VIDD, COPD.

\section{Article History}

Received: March 29, 2019

Revised: June 18, 2019

Accepted: June 20, 2019

\section{INTRODUCTION}

Ventilator-Induced Diaphragmatic Dysfunction (VIDD) is a well-known problem to health care professionals working with patients during weaning from the ventilator ever since Levine et al. have demonstrated VIDD in human transplant donors [1]. VIDD is difficult to prove but its consequences are easily recognizable in patients needing prolonged weaning. Patients suffering from VIDD are more difficult to wean from the ventilator. These patients tend to develop cough problems and consequently mucus retention, atelectasis and ventilatorassociated pneumonia.

\footnotetext{
* Address correspondence to this author at the Marienkrankenhaus Kassel, Marburger Str. 85, 34127 Kassel, Germany; Tel: 004956180731212 ;
}

Fax:004956180734200; E-mails: a.bastian@marienkrankenhaus-kassel.de
VIDD is the major reason for diaphragmatic dysfunction in patients who need prolonged mechanical ventilation but a lot of these patients suffer from additional components also contributing to their diaphragmatic dysfunction: i) it could be aggravated by phrenic nerve injury due to cardiac surgery or ii) diaphragmatic dysfunction might have been preexisting maybe due to severe COPD or a before known or undiagnosed neuromuscular disease.

There are reports that give some hope for a potential improvement of diaphragmatic dysfunction over a period of up to 18 months [2]. Some patients with diaphragmatic dysfunction and diaphragmatic paralysis that is due to neuralgic amyotrophy typically have complete recovery or improvement in symptoms in 1 to 1.5 years. Recovery of 
phrenic nerve function is possible in different kinds of nerve injury and takes up to 18 months [3]. Recovery times may be somewhat shorter in patients who have diaphragmatic dysfunction after cardiac surgery [4].

A definite measurement of VIDD is difficult. From all the different sonographic methods proposed by the literature, we routinely measure the lung silhouette movement on both sides of the diaphragm. Here, the up and downward movement of the lungs functions as a surrogate for diaphragmatic force. According to our experience in COPD patients, this method is reliable and can easily be performed [5].

The purpose of our study was to describe the changes in diaphragmatic function, evaluated sonographically, after very prolonged weaning.

\section{METHODS}

We performed a prospective single-center study with patients inclusion from October 2013 until April 2014 - with the follow-up period until October 2015. The Marienkrankenhaus is a general teaching hospital with 210 beds. Part of the department of pneumonology of the Marienkrankenhaus is the weaning center including 15 ICU beds and a 24-bed ward for non invasively ventilated patients. The weaning center is certified by the German Society of Pneumonology.

Inclusion criteria: We included only patients admitted from other hospitals with at least 4 weeks of preceding invasive mechanical ventilation. All these patients had already fulfilled the criteria for prolonged weaning in the admitting hospital (at least 3 failed weaning attempts). At the time of inclusion in the study, patients had to be able to breathe at least 10 minutes over a t-piece and sit upright for at least 5 minutes; they had to be able to cooperate especially regarding breathing maneuvers.

\subsection{Sonographic Examination}

Lung silhouette measurement of the upward- and downward movement of the lung silhouette

All participants were evaluated in a sitting position. Ultrasound was performed with a Hitachi ultrasound system (Sono MR, EUB-7500 HV) using a $3.5 \mathrm{MHz}$ curved probe. The transducer was placed at the lowest part of the lung silhouette in the scapular line (Fig. 1).

The patient is sitting; the transducer is placed at the lowest point of the lung silhouette in the scapular line. While the patient breathes as deeply as possible a video sequence is performed. Afterward, the distance between maximal inspiration and maximal expiration can be measured.

The participant was instructed to exhale as deeply as possible (to residual volume) and then to inhale deeply to total lung capacity. This maneuver was recorded by ultrasound measuring the distance between the highest and the lowest point of the lung silhouette (Figs. 2a and 2b). This measurement was performed on the right and the left side of the chest in the scapular line.

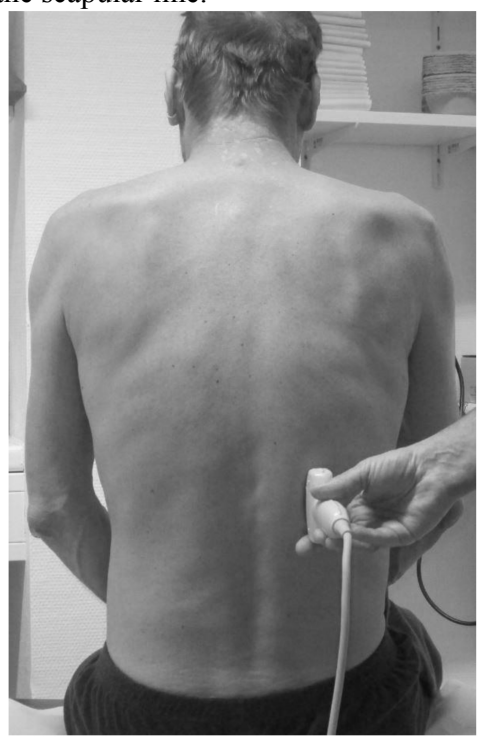

Fig. (1). Sonographic measurement of the up- and downward movement of the lung silhouette - here on the right side.

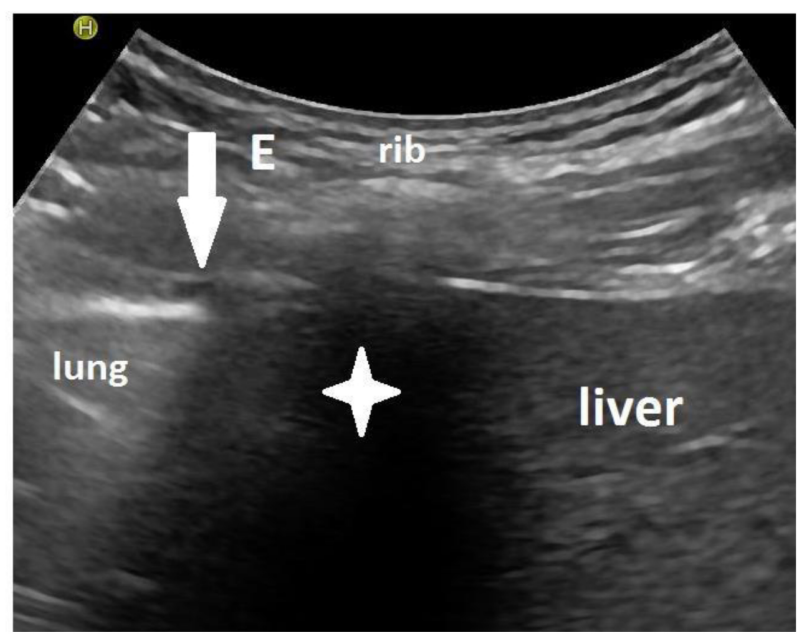

Fig. (2a). Sonographic measurement of the up- and downward movement of the lung silhouette - here on the right side. Underwards the arrowhead marked with E the different echogenicity separates between lung and liver tissue at maximal end expiration. The cross indicates the rib`s ultrasound shadow.

\subsection{Sonographic Follow Up}

We had planned follow up visits 6 weeks, $3,6,12$, and 18 months after inclusion but many of these visits had to be postponed not only because of health issues but also because the patients had other priorities. 


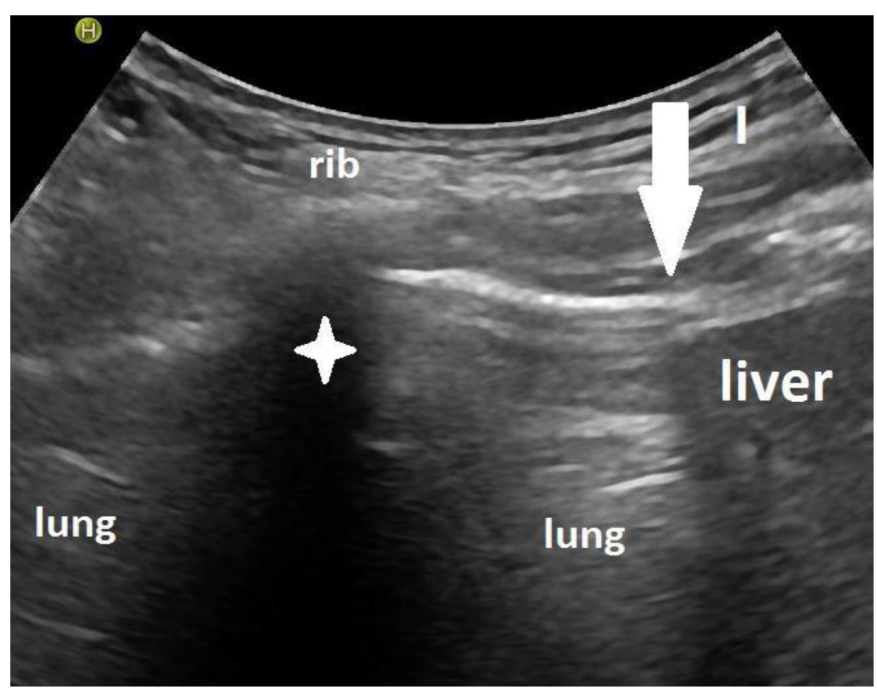

Fig. (2b). Sonographic measurement of the up- and downward movement of the lung silhouette - here on the right side. Underwards the arrowhead marked with I the different echogenicity separates between the lung and liver tissue at maximal end inspiration. To measure the distance the lung silhouette moved the distance between the E point in figure $2 \mathrm{a}$ and the I point in figure $2 \mathrm{~b}$ has to be measured by scrolling the sonographic video. The cross indicates the rib`s ultrasound shadow.

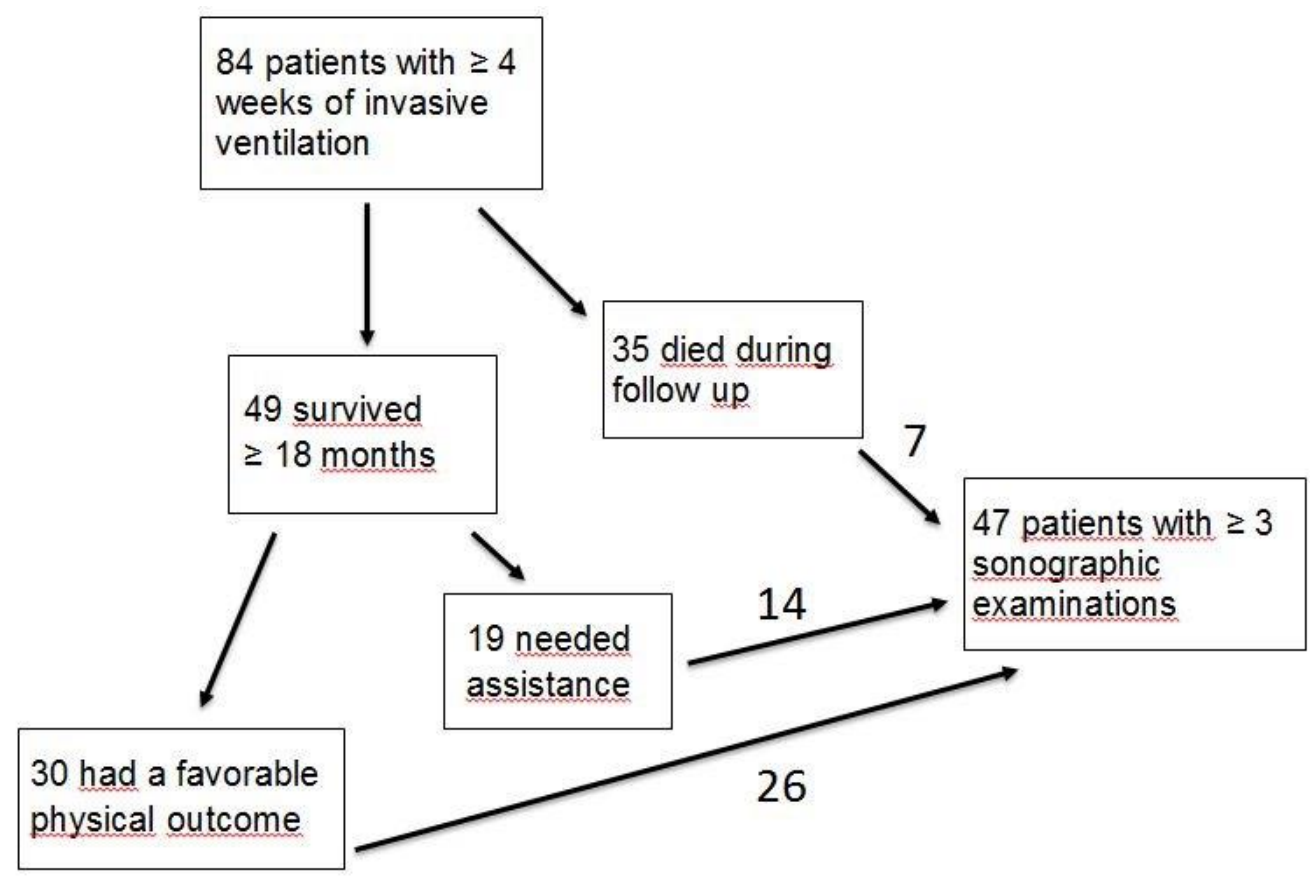

Flowchart: 84 patients fulfilled the inclusion criteria - 49 survived, 35 died during the 18 months follow up. From the survivors, 30 had a favorable physical outcome, 19 needed assistance. From the initial 84 patient, 47 had at least 3 sonographic follow up investigations. These were included in the diaphragm mobility follow up investigations. This group contains 7 patients who died later during follow up, and 40 who survived ( 26 patients with a favorable outcome and 14 who needed assistance at the end of the follow-up period).

\subsection{Endpoints}

Different endpoints were investigated: survival after 1.5 years, outcome differentiating between independent autonomous life and need for assistance and relation of survival and diaphragm mobility (Flowchart).

\subsection{Definition of Outcome}

Not satisfying outcome means the need of newly initiated noninvasive ventilation or need of assistance at home or living in a nursing home.

\subsection{Data Analysis}

ROC-analyses were performed for the maximal diaphragmatic mobility improvement with respect to outcome and survival after 18 months. The influence of the improvement was assessed with a logistic regression model and risk factors for survival were studied with a Cox regression.

The significance level was set to $=5 \%$ for all statistical 
tests. All analyses were performed with the statistic software R (version 3.1.2, www.r-project.org).

ROC analysis: 2 endpoints were investigated in relation to diaphragmatic function: survival after 1.5 years and outcome differentiating between independent autonomous life and need of assistance in daily life.

\subsection{Ethics}

The institutional ethics committee of the Marienkrankenhaus hospital approved the study (MKH 08/2012). All participating patients gave their informed written consent including them in the weaning registry of the German Society of Pneumonology.

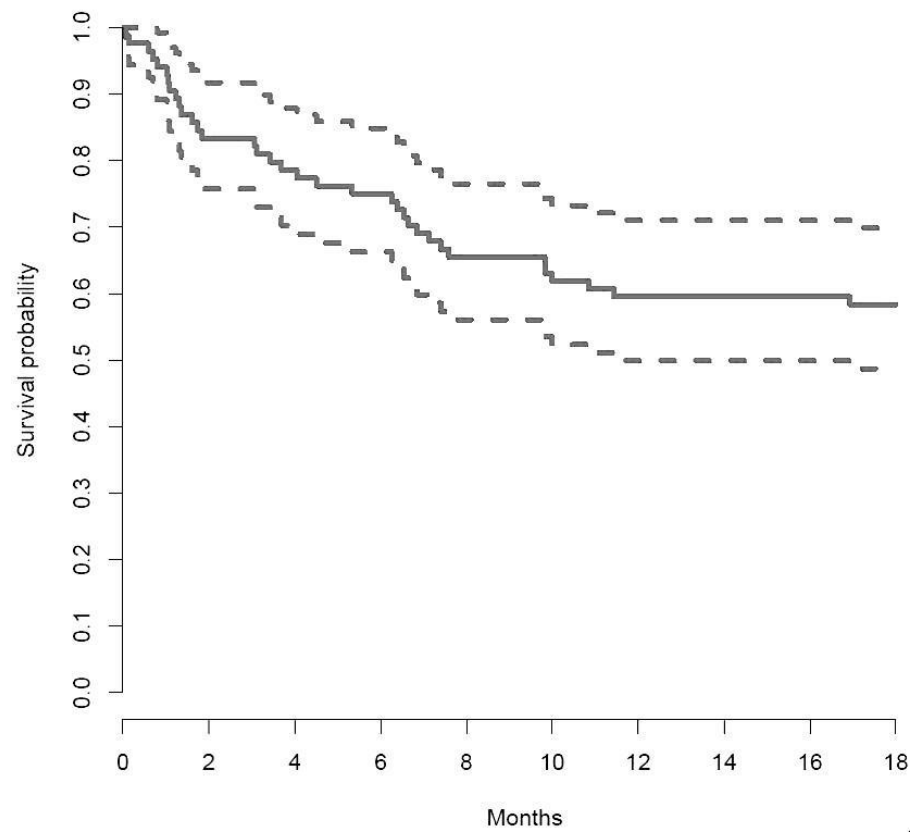

Fig. (3). Survival probability: Survival probability and standard deviation (- - -) of all 84 patients with a prolonged weaning time of more than 4 weeks before they were admitted to our weaning unit over a time period of 18 months. 49 of the 84 patients $(58.3 \%)$ survived.

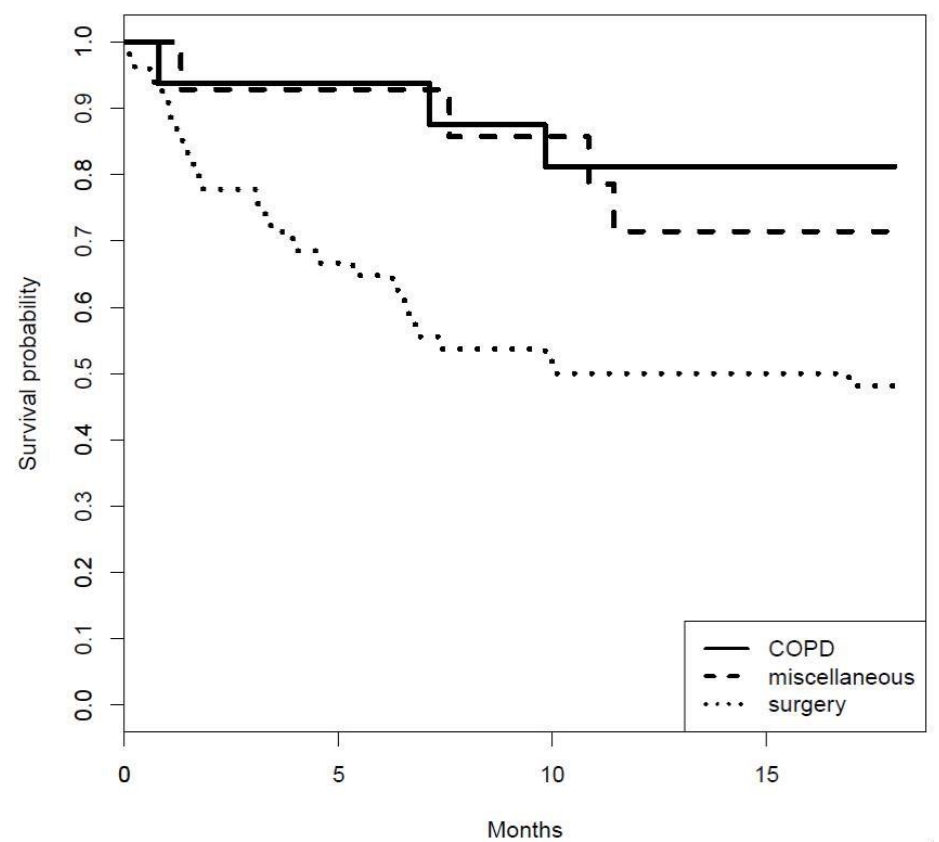

Fig. (4). Survival probability of the different subgroups of patients with a prolonged weaning time of more than 4 weeks before they were admitted to our weaning unit over a time period of 18 months - 54 patients after surgery, 16 patients with COPD exacerbations, and 14 patients with different other reasons for prolonged weaning. Especially the post surgery patients had a worse outcome but this is statistically not significant because these patients were older and had more accompanying disease. 


\section{RESULTS}

84 patients were included: 54 after surgery (cardiac surgery or upper abdominal surgery); 16 with COPD exacerbations and 14 with varying other reasons.

\subsection{First Endpoint: Survival After 1.5 Years}

From the total 84 patients, 49 survived and 35 died within 1.5 years (Fig. 3). 30 of the survivors had a good outcome and 19 were in need of assistance in daily life.

Fig. (4) shows the survival curve of the different subgroups of patients. Especially the post-surgery patients had a worse outcome but this is statistically not significant because these patients were older and had more accompanying diseases.

From the total of 84 patient, 16 (19\%) were older than 80 years, $5(31.25 \%)$ of these survived ( 2 with a good outcome and 3 with the need for assistance) and $11(68.75 \%)$ died.

\subsection{Sonographically Measured Diaphragm Mobility}

Patients: There is a mismatch in survival between the whole patient group and the patients included in the sonographic examinations because more patients who died had not a long enough time to allow for the at least 3 sonographic analyses (see flowchart). This does not influence the data of the 47 patients who were sonographically examined.

\subsection{Thresholds for Diaphragm Mobility and Survival and for Diaphragm Mobility and Outcome}

We defined the statistically best thresholds of diaphragm mobility to separate between "to survive" and ,to die" and between "satisfactory outcome" and "need for assistance". The statistically best threshold to discriminate between "to survive" and "to die" was $15.5 \mathrm{~mm}$ on the left diaphragm. The statistically best threshold to discriminate between "satisfactory outcome" and "need for assistance" was $20 \mathrm{~mm}$ also on the left diaphragm.

\subsection{Survival and Diaphragm Mobility}

47 patients had $\geq 3$ measurements of diaphragm mobility over at least 6 months and were included in the diaphragm mobility analyses. Of these 47 patients, 31 had a diaphragmatic mobility improvement of $>15.5 \mathrm{~mm}$ on the left side - 29 survived, 2 died; if the diaphragmatic mobility improvement was $<15.5 \mathrm{~mm}, 11$ survived and 5 died. An increase of diaphragm mobility on the left side of $>15.5 \mathrm{~mm}$ at any given time point predicted a survival probability of $93.55 \%$ (Table 1) whereas survival was only $68.75 \%$ when the diaphragmatic mobility improvement on the left side was $<15.5 \mathrm{~mm}$.

Table 1. Optimal cutoff point for the differences in diaphragm mobility, regarding survival/death as well as the corresponding sensitivity, specificity, positive and negative predictive value.

\begin{tabular}{|l|c|c|c|c|c|c|}
\hline Outcome & Diaphragm & $\begin{array}{c}\text { Cutoff } \\
(\mathbf{m m})\end{array}$ & Sensitivity & Specificity & PPV & NPV \\
\hline Survival & Left & 15.5 & 71.43 & 72.5 & 31.25 & 93.55 \\
\hline Survival & Right & 21.5 & 85.71 & 57.5 & 26.09 & 95.83 \\
\hline
\end{tabular}

\subsection{Second Endpoint: Outcome:}

\subsubsection{Outcome Differentiating Between Independent Auto- nomous Life and Need for Assistance}

Of the 49 patients who survived $30(61.2 \%)$ had a good outcome and 19 (38.8\%) were in need of assistance in daily life.

25 patients had a diaphragmatic mobility improvement of $>$ $20 \mathrm{~mm}$ on the left side; out of these 19 had a good outcome, 4 had a not satisfying outcome (need of new noninvasive ventilation or need of assistance) and 2 died; if the diaphragmatic mobility improvement was $<20 \mathrm{~mm}$ only 7 had a good outcome, 10 had a not favorable outcome and 5 died.

An increase of diaphragm mobility on the left side of $>20$ $\mathrm{mm}$ at any given time point predicted an independent autonomous life 18 months after study inclusion with a probability of $82.1 \%$ (Table 2 ). An increase of diaphragm mobility on the left side of $<20 \mathrm{~mm}$ at any time point predicted an independent autonomous life 18 months after study inclusion with a probability of $41.18 \%$.

Table 2. Optimal cutoff point for the differences in diaphragm mobility, regarding the outcome within the group of the survivors - defined here as "functionally well" against "in need for help" - as well as the corresponding sensitivity, specificity, positive and negative predictive value.

\begin{tabular}{|l|c|c|c|c|c|c|}
\hline Outcome & Diaphragm & $\begin{array}{c}\text { Cutoff } \\
(\mathbf{m m})\end{array}$ & Sensitivity & Specificity & PPV & NPV \\
\hline Positive & Left & 20 & 73.08 & 71.43 & 82.61 & 58.82 \\
\hline Positive & Right & 21.5 & 65.38 & 57.14 & 73.91 & 47.06 \\
\hline
\end{tabular}

\section{DISCUSSION}

\subsection{Outcome of Prolonged Weaning}

According to Lamas et al., 5 - 10\% of patients who have survived a catastrophic illness or surgical procedure requiring intubation remain dependent on mechanical ventilation [6]. More than half of them do not survive their first year and only $12 \%$ are at home and functionally independent 1-year after their acute illness. Studies investigating weaning patients post cardiac surgery report similar results. $3-6 \%$ of patients after cardiac surgery require prolonged ventilation [7 - 11]. A problem comparing data from the different studies is the difference in definitions of "delayed extubation"; ranging from less than 24 hours to 7 days and more than 2 weeks. In an extensive review, Damuth et al. identified 29 high-quality studies dealing with the outcome of patients on prolonged mechanical ventilation of at least 2 weeks worldwide [12]. Among these, the pooled survival after 1 year was $38 \%$; only $50 \%$ were successfully liberated from mechanical ventilation and only $19 \%$ were discharged to their previous home surroundings.

Our study patients had a survival rate of $58.3 \%$ (49 out of 84 ) after 18 months. By then, $60.1 \%$ of these patients were at home and functionally independent. The others lived in home care facilities or needed assistance in their own home. Our study's mortality rate is lower than the mortality rates from 
other studies. This might demonstrate an improvement in the medical treatment of weaning patients over the last decades. Differences in outcome result also from the different patient groups included in different studies. Most studies include many ARDS patients whereas most of our patients are post surgery (cardiac surgery) and COPD patients. Their outcome is better. The better outcome of our patients does not automatically reflect better medical care but is primarily a result of the heterogeneity of weaning patients.

Other newer studies support this suggestion and also report lower mortality rates. The WIND study with a higher number of patients included examined only the in-hospital mortality [13]. 235 patients who had needed more than 7 days after the first spontaneous breathing trial had in-hospital mortality of $29.8 \%$ - long time mortality data, are not given. In addition, the Funk study with 37 patients with prolonged weaning demonstrated in-hospital mortality of $32 \%$ [14].

An additional point of interest is the survival of old patients. Schönhofer et al. investigated 403 patients with at least 2 weeks of mechanical ventilation. Survival rates after hospital discharge were $37 \%$ at 1 year and $32 \%$ at 2 years [15]. Study patients older than 80 years had an in-hospital mortality rate higher than $50 \%$. Other authors demonstrated an even worse survival of the elderly. Swinburne et al. found a $91 \%$ mortality for patients older than 80 years who needed mechanical ventilation for more than 15 days [16]. Cohen found a mortality rate of $78 \%$ if patients older than 80 years were mechanically ventilated longer than only 3 days [17].

From the total 84 patients, we investigated that only 16 patients (19\%) were older than 80 years. $5(31.25 \%)$ of these survived the 18 months observation period ( 2 with a good outcome and 3 with the need for assistance) and $11(68,75 \%)$ died. The survival rate of 5 out of 16 after 18 months is better than the published data, but worse than the younger patients group.

Up to now, there is no standardized sonographic method to examine the force of the diaphragm. From all the different sonographic methods proposed by the literature, we routinely measure the lung silhouette movement on both sides of the diaphragm [5]. Some researchers have investigated diaphragmatic function in mechanically ventilated patients. Lately, the measurements of the diaphragm thickness and the thickening fraction on the right side alone or on both sides of the diaphragm have become the preferred sonographic methods [18 - 23]. These approaches were used to investigate the mobility of the diaphragm only during the first days after intubation demonstrating a decline of diaphragmatic thickness and the thickening fraction. Other groups used diaphragm sonography to predict extubation success and compared the results to the results of the Rapid Shallow Breathing Index (RSBI) [24].

We started to measure the change of the diaphragmatic function at a much later stage, when the daily periods of invasive ventilation could be reduced. We started our investigations when the patients could just breathe for short periods by themselves again after at least 4 weeks of unsuccessful weaning in another hospital. We could demonstrate that the initial measurements of diaphragmatic dysfunction would not help to predict weaning outcome. But if diaphragmatic dysfunction improved over time regardless of how much time it took, it could help to predict the outcome. If diaphragmatic dysfunction improvement was more than $15.5 \mathrm{~mm}$ on the left side, the probability of survival was $94 \%$ with a probability of $76 \%$ to have a satisfying outcome, and if the improvement of diaphragm mobility was even more than $20 \mathrm{~mm}$ on the left side, the patients had a satisfactory outcome probability of $83 \%$ in relation to their respective medical condition before the ventilation period had begun. Improvement of diaphragmatic dysfunction on the right side was also associated with an improved outcome of the patient but the scale of improvement was not as pronounced as on the left side. We can only guess why the left side improvement is more relevant. One possibility might involve cardiac surgery patients. The left side approach might inflict more damage to the left hemidiaphragm and regaining former strength is more important. But at present, there is no proof for this theory.

\section{AUTHORS' CONTRIBUTIONS TO THE STUDY}

Idea and concept: $\mathrm{AB}, \mathrm{NG}$

Sonographic examinations: AB, NG, AS, MB, SV

Patients`selections: AB, NG, AS, MB, SV, HG

Writing the manuscript: $\mathrm{AB}$

Data sampling: $\mathrm{AB}, \mathrm{NG}, \mathrm{HG}$

Statistics: XS

\section{ETHICS APPROVAL AND CONSENT TO PARTI- CIPATE}

The institutional ethics committee of the Marienkrankenhaus hospital approved the study (MKH 08/2012).

\section{HUMAN AND ANIMAL RIGHTS}

No animals were used in this research. All human research procedures followed were in accordance with the ethical standards of the committee responsible for human experimentation (institutional and national), and with the Helsinki Declaration of 1975, as revised in 2013.

\section{CONSENT FOR PUBLICATION}

All participating patients gave their informed written consent.

\section{AVAILABILITY OF DATA AND MATERIALS}

Not applicable.

\section{FUNDING}

None.

\section{CONFLICT OF INTEREST}

The authors declare no conflict of interest, financial or otherwise. 


\section{ACKNOWLEDGEMENTS}

Declared none.

\section{REFERENCES}

[1] Levine S, Nguyen $\mathrm{T}$, Taylor $\mathrm{N}$, et al. Rapid disuse atrophy of diaphragm fibers in mechanically ventilated humans. N Engl J Med 2008; 358(13): 1327-35.

[http://dx.doi.org/10.1056/NEJMoa070447] [PMID: 18367735]

[2] McCool FD, Tzelepis GE. Dysfunction of the diaphragm. N Engl J Med 2012; 366(10): 932-42

[http://dx.doi.org/10.1056/NEJMra1007236] [PMID: 22397655]

[3] Hughes PD, Polkey MI, Moxham J, Green M. Long-term recovery of diaphragm strength in neuralgic amyotrophy. Eur Respir J 1999; 13(2): 379-84.

[http://dx.doi.org/10.1183/09031936.99.13237999] [PMID: 10065685]

[4] Efthimiou J, Butler J, Woodham C, Benson MK, Westaby S. Diaphragm paralysis following cardiac surgery: Role of phrenic nerve cold injury. Ann Thorac Surg 1991; 52(4): 1005-8. [http://dx.doi.org/10.1016/0003-4975(91)91268-Z] [PMID: 1929616]

[5] Scheibe N, Sosnowski N, Pinkhasik A, Vonderbank S, Bastian A. Sonographic evaluation of diaphragmatic dysfunction in COPD patients. Int J Chron Obstruct Pulmon Dis 2015; 10: 1925-30. [PMID: 26392767]

[6] Lamas D. Chronic critical illness. N Engl J Med 2014; 370(2): 175-7. [http://dx.doi.org/10.1056/NEJMms1310675] [PMID: 24401058]

[7] Engoren M, Buderer NF, Zacharias A. Long-term survival and health status after prolonged mechanical ventilation after cardiac surgery. Crit Care Med 2000; 28(8): 2742-9

[http://dx.doi.org/10.1097/00003246-200008000-00010] [PMID: 1096 6245]

[8] LoCicero J III, McCann B, Massad M, Joob AW. Prolonged ventilatory support after open-heart surgery. Crit Care Med 1992; 20(7): 990-2.

[http://dx.doi.org/10.1097/00003246-199207000-00015] [PMID: 1617993]

[9] Arom KV, Emery RW, Petersen RJ, Schwartz M. Cost-effectiveness and predictors of early extubation. Ann Thorac Surg 1995; 60(1): $127-32$

[http://dx.doi.org/10.1016/S0003-4975(95)00356-8] [PMID: 7598574]

[10] Bezanson JL, Deaton C, Craver J, Jones E, Guyton RA, Weintraub WS. Predictors and outcomes associated with early extubation in older adults undergoing coronary artery bypass surgery. Am J Crit Care 2001; 10(6): 383-90. [PMID: 11688605]

[11] Konstantakos AK, Lee JH. Optimizing timing of early extubation in coronary artery bypass surgery patients. Ann Thorac Surg 2000; 69(6): $1842-5$

[http://dx.doi.org/10.1016/S0003-4975(00)01248-0] [PMID: 1089 2934]

[12] Damuth E, Mitchell JA, Bartock JL, Roberts BW, Trzeciak S. Longterm survival of critically ill patients treated with prolonged mechanical ventilation: A systematic review and meta-analysis. Lancet
Respir Med 2015; 3(7): 544-53

[http://dx.doi.org/10.1016/S2213-2600(15)00150-2] [PMID: 2600 3390]

[13] Béduneau G, Pham T, Schortgen F, et al. Epidemiology of weaning outcome according to a new definition. The WIND study. Am J Respir Crit Care Med 2017; 195(6): 772-83.

[http://dx.doi.org/10.1164/rccm.201602-0320OC] [PMID: 27626706]

[14] Funk GC, Anders S, Breyer MK, et al. Incidence and outcome of weaning from mechanical ventilation according to new categories. Eur Respir J 2010; 35(1): 88-94.

[http://dx.doi.org/10.1183/09031936.00056909] [PMID: 19541716]

[15] Schönhofer B, Euteneuer S, Nava S, Suchi S, Köhler D. Survival of mechanically ventilated patients admitted to a specialised weaning centre. Intensive Care Med 2002; 28(7): 908-16.

[http://dx.doi.org/10.1007/s00134-002-1287-5] [PMID: 12122529]

[16] Swinburne AJ, Fedullo AJ, Bixby K, Lee DK, Wahl GW. Respiratory failure in the elderly. Analysis of outcome after treatment with mechanical ventilation. Arch Intern Med 1993; 153(14): 1657-62. [http://dx.doi.org/10.1001/archinte.1993.00410140039005] [PMID 8333803]

[17] Cohen IL, Lambrinos J, Fein IA. Mechanical ventilation for the elderly patient in intensive care. Incremental changes and benefits. JAMA 1993; 269(8): 1025-9.

[http://dx.doi.org/10.1001/jama.1993.03500080073035] [PMID: 8429 584]

[18] Ferrari G, De Filippi G, Elia F, Panero F, Volpicelli G, Aprà F. Diaphragm ultrasound as a new index of discontinuation from mechanical ventilation. Crit Ultrasound J 2014; 6(1): 8 .

[http://dx.doi.org/10.1186/2036-7902-6-8] [PMID: 24949192]

[19] Lerolle N, Guérot E, Dimassi S, et al. Ultrasonographic diagnostic criterion for severe diaphragmatic dysfunction after cardiac surgery. Chest 2009; 135(2): 401-7.

[http://dx.doi.org/10.1378/chest.08-1531] [PMID: 18753469]

[20] Goligher EC, Fan E, Herridge MS, et al. Evolution of diaphragm thickness during mechanical ventilation. Impact of inspiratory effort. Am J Respir Crit Care Med 2015; 192(9): 1080-8. [http://dx.doi.org/10.1164/rccm.201503-0620OC] [PMID: 26167730]

[21] Grosu HB, Lee YI, Lee J, Eden E, Eikermann M, Rose KM. Diaphragm muscle thinning in patients who are mechanically ventilated. Chest 2012; 142(6): 1455-60.

[http://dx.doi.org/10.1378/chest.11-1638] [PMID: 23364680]

[22] Francis CA, Hoffer JA, Reynolds S. Ultrasonographic evaluation of diaphragm thickness during mechanical ventilation in intensive care patients. Am J Crit Care 2016; 25(1): e1-8.

[http://dx.doi.org/10.4037/ajcc2016563] [PMID: 26724302]

[23] Schepens T, Verbrugghe W, Dams K, Corthouts B, Parizel PM, Jorens PG. The course of diaphragm atrophy in ventilated patients assessed with ultrasound: a longitudinal cohort study. Crit Care 2015; 19(19): 422.

[http://dx.doi.org/10.1186/s13054-015-1141-0] [PMID: 26639081]

[24] Spadaro S, Grasso S, Mauri $\mathrm{T}$, et al. Can diaphragmatic ultrasonography performed during the T-tube trial predict weaning failure? The role of diaphragmatic rapid shallow breathing index. Crit Care 2016; 20(1): 305 .

[http://dx.doi.org/10.1186/s13054-016-1479-y] [PMID: 27677861]

C) 2019 Gibis et al.

This is an open access article distributed under the terms of the Creative Commons Attribution 4.0 International Public License (CC-BY 4.0), a copy of which is available at: https://creativecommons.org/licenses/by/4.0/legalcode. This license permits unrestricted use, distribution, and reproduction in any medium, provided the original author and source are credited. 